\title{
Additive Manufacturing Assisting the Design of Closed - Die Forgings Stefan Szczepanik ${ }^{1, a^{*}}$, Piotr Nikiel ${ }^{2, b}$ \\ ${ }^{1,2} \mathrm{AGH}$ University of Science and Technology, al. Mickiewicza 30 30-065 Krakow, Poland

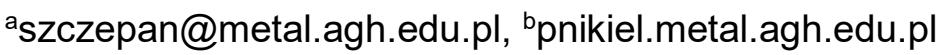

Keywords: closed-die forging, design of the forging process, CAD documentation, process FEM testing, 3D printing

\begin{abstract}
Rebielskij-type design of a rolled con rod preform and appropriate upper and lower dies are presented. The proposed process was tested by Simufact Forming program and modifications made to satisfy the criteria of shape, stress and strain state and temperature distribution during processing. Based on the CAD documentation, a STL file was prepared for 3D polymer printing the die, the con rod preform and the forging. The results will enable $3 \mathrm{D}$ printing of prototypes in the appropriate metallic materials, leading to tool manufacture and processing in industrial conditions.
\end{abstract}

\section{Introduction}

The advantages and disadvantages of conventional forging, schematically summarized in Fig.1, are well known $[1,2]$. In practice, production rarely manages to get the required product, without the needed correction of the preform and/or die shape. Manufacturing complex geometries which are impossible to obtain by machining is now attained by additive manufacturing.

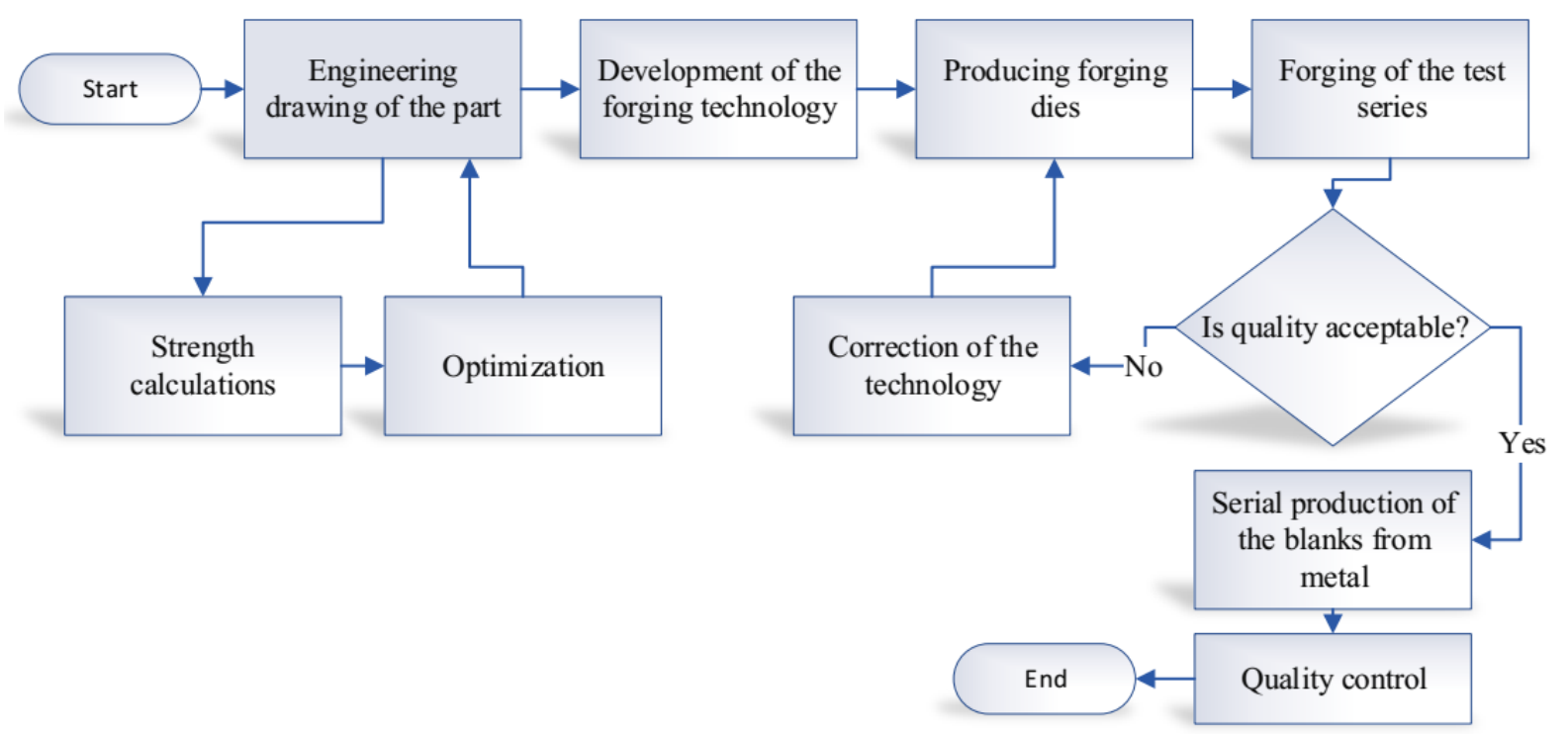

Figure 1. Process chain for forging products by conventional technology

Application of additive manufacturing to die - forging has been reported e.g. by Schwam and Silwal [3] and Hirschvogel [4]. CAD software, which enables producing complicated parts, and MES simulations programs are its inseparable components. Such software, assisted by 3D printing, can be used in developing the conventional process of forging. Figure 2 summarises a possible additive manufacturing chain involving initial 3D polymer printing of models of the die and preform forging, in every stage of pressing, and the required shape and size of the metal component. This procedure enables verification of their shapes and possible redesign at the polymer model stage. Manufacturing from appropriate metallic material takes place after verification of polymer printed models. Thus a cost saving results. In this paper the sequence of stages of forging of an aluminium alloy conrod, up to $3 \mathrm{D}$ polymer printing of the required shape and size, is presented. 


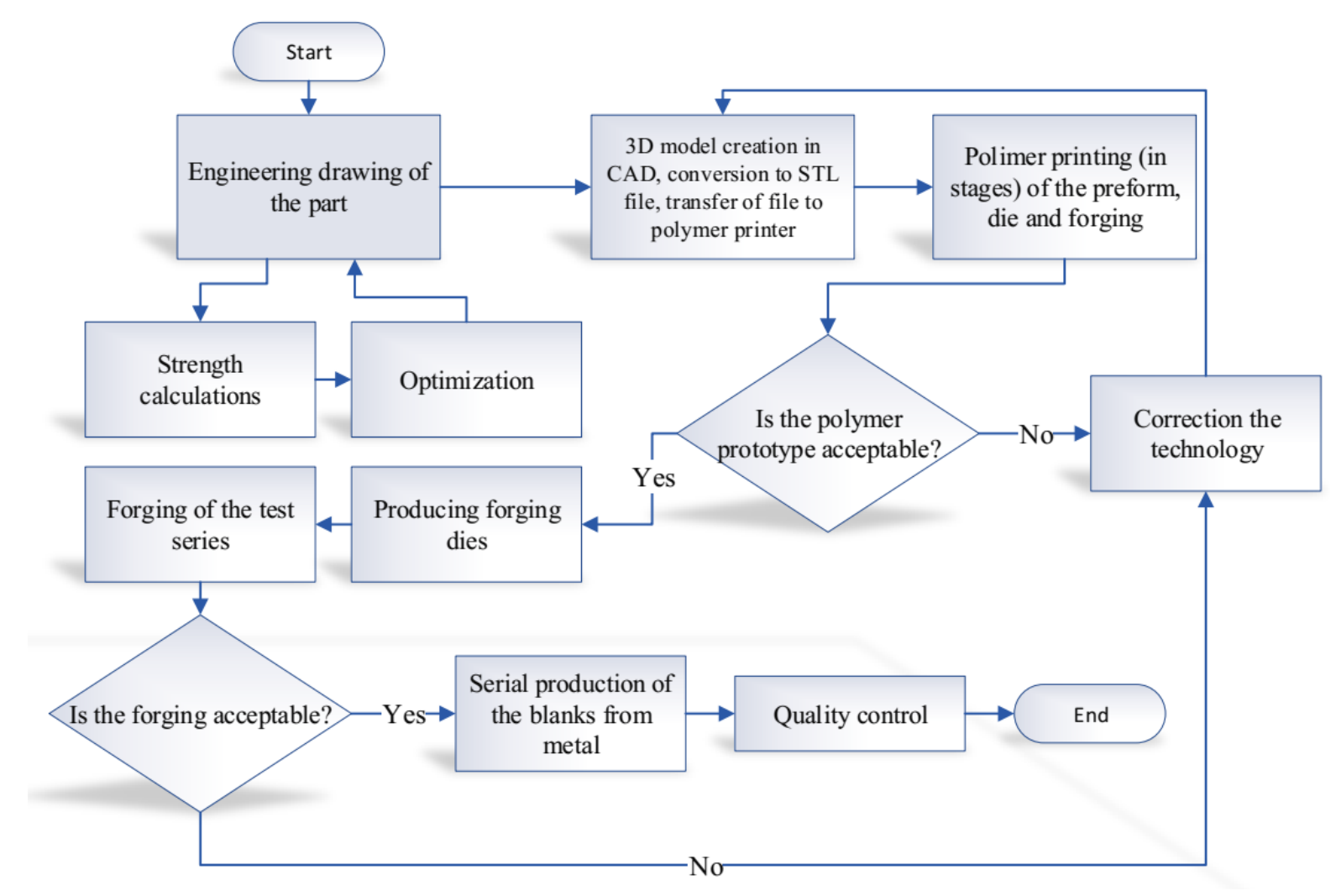

Figure 2. Process chain for additive manufacturing of products

\section{Experimental Procedures}

Stages of designing the technology in both cases, Figs. 1 and 2, are only initially the same.

For the modified technology the steps are:

Step 1. A technical drawing of the con rod. Drawing the shape of the forging and preform, by the method of Rebielskij [5], and of the die set [2,5].

Step 2. 3D in creation of preform and die in CAD models for FEM simulation, optimization of the forging process from Rebielskij-type preform using Simufact Forming program for 7022 aluminium alloy.

Step 3. A Conversion to STL files 3D models of the conrod, the preform forging, the forging and the die set.

Step 4. Polymer printing (in stages) of the preform, the die set and the forging.

Step 5. Critical comparison of resultant polymer model forging with dimensional specifications.

Step 6. (if required) Modifications to die and perform models. Repeat of Steps 4 and 5.

\section{Results}

\section{Step 1. Technical drawing of the con rod and the forged part}

Figure 3 shows the engineering drawing of the con rod and the forged part. By the method of Rebielskij, drawings of the forging, the preform and the die set incorporating a flash gutter were obtained [5]. Illustrated in Fig. 4 are drawings of the preform and the forging. Parameters of the forging: $290 \mathrm{~mm}$ circumference, $12213 \mathrm{~mm}^{3}$ volume, $2104.4 \mathrm{~mm}^{2}$ surface of a cross section needed. 
a)
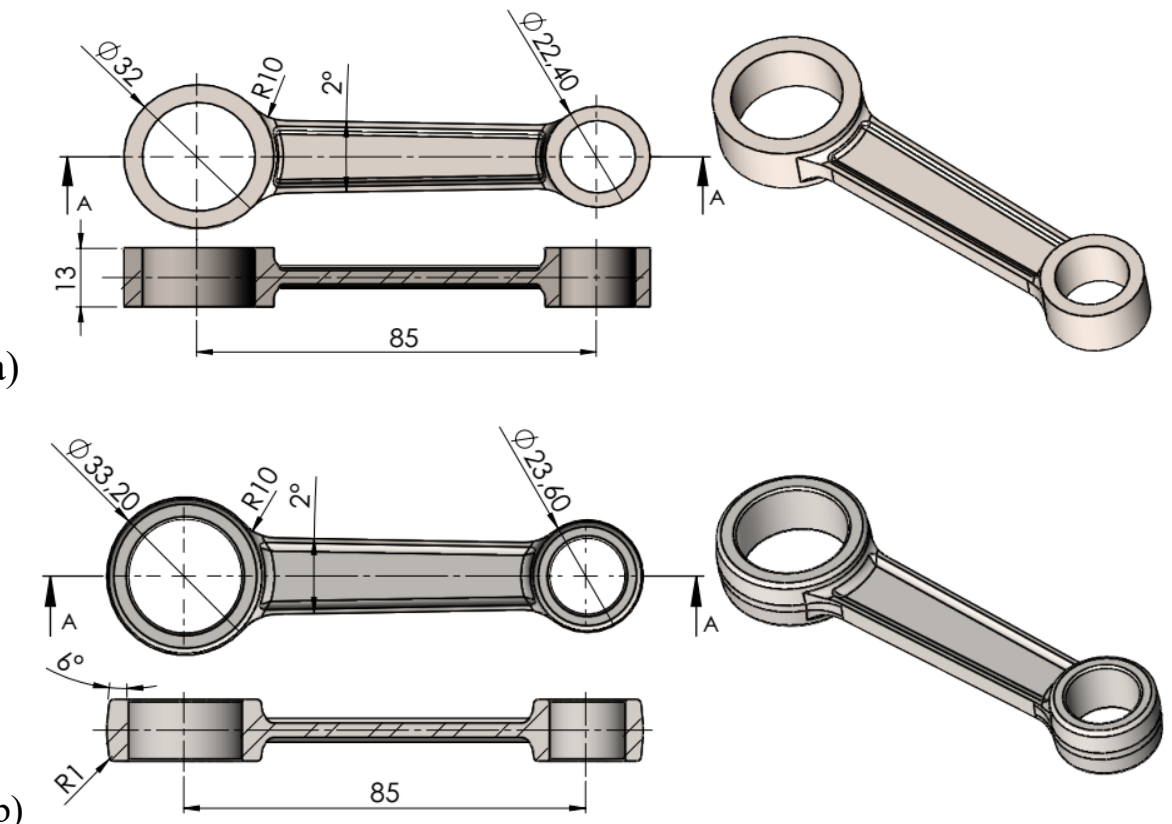

Figure 3. Technical drawing of: (a) the conrod (10428 $\mathrm{mm}^{3}$ volume $28.3 \mathrm{~g}$ weight), and (b) the part after forging (12213 $\mathrm{mm}^{3}$ volume, $33.2 \mathrm{~g}$ weight)

a)

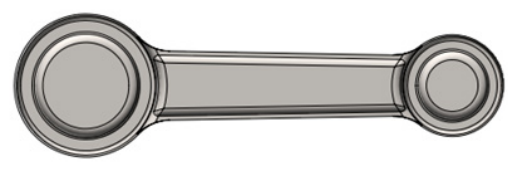

.

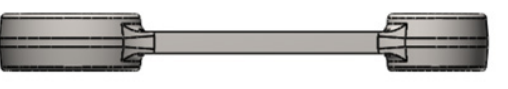

b)

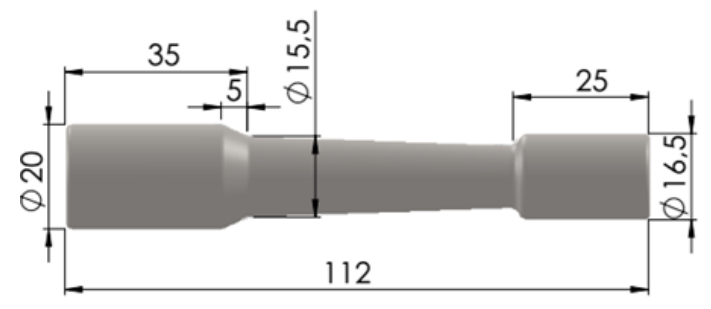

Figure 4. The shape of the forging with a bottom - a and b - the rolled preform by the method of Rebielskij [5]

Steps 2 and 6. FEM simulation for optimization of the forging process from Rebielskij-type preform using Simufact Forming program

Simufact forming FEM simulation, based on MSC Marc solver, was used. The data for simulation were: $250 \mathrm{~mm} / \mathrm{s}$ for the punch speed, material characterization A17022, $460{ }^{\circ} \mathrm{C}$ for the workpiece temperature, $350^{\circ} \mathrm{C}$ for the die temperature and 0.3 for friction coefficient. Material characterization of Al7022 aluminium alloy at temperature range $360-440{ }^{\circ} \mathrm{C}$ is shown in Figure 5. The simulation results comprise quality of filling of the die shape, distribution of the effective plastic strain, effective stress, forging force and energy consumption. Geometrical model for the simulation is shown in Figure 6.

The first simulation calculation was for Rebielskij original preform. CAD 3D of the model Rebielskij calculations yielded the preform illustrated in Fig. 6(a). Geometrical model for simulation is shown in Figure 6b. The calculated effective strain and stress are shown in Fig.7. Quality of filling the die shape needed a correction of the diameter of the preform (Step 6). The results of the second simulation for corrected preform are shown in Figure 8. 


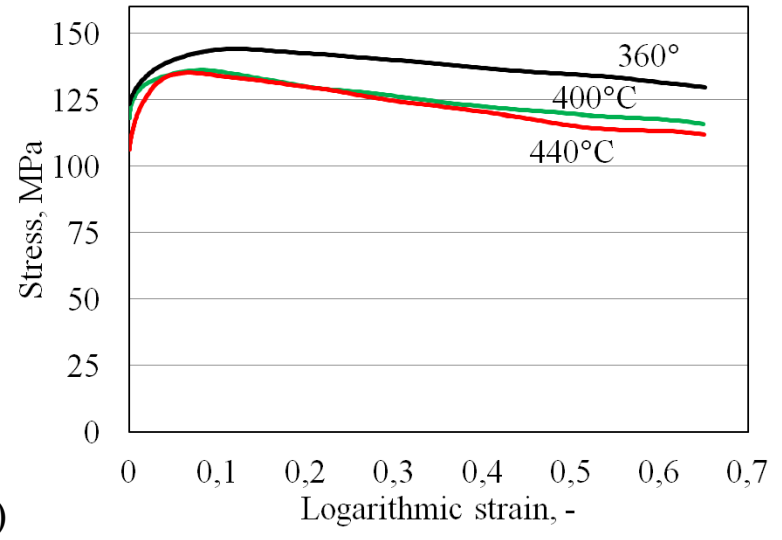

a)

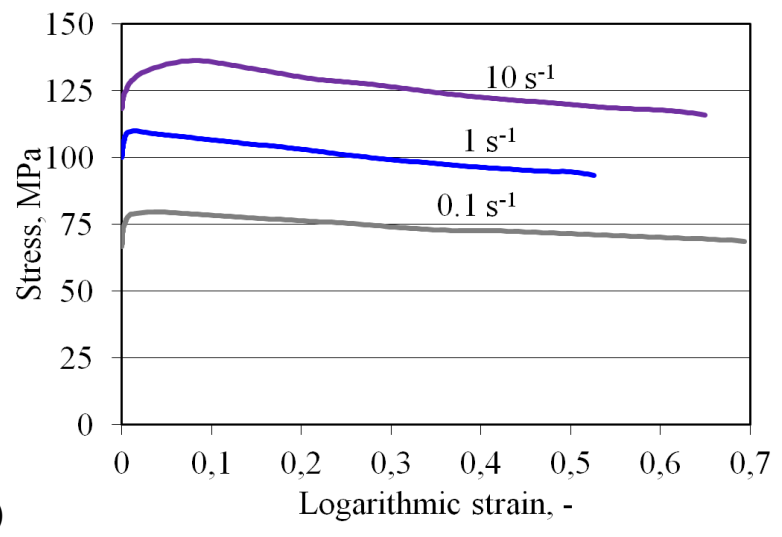

Figure 5. Stress- strain relationships for 7022 aluminium alloy at 360,400 and $440^{\circ} \mathrm{C}$ at a strain rate of $10 \mathrm{~s}^{-1}(\mathrm{a})$, and at $400^{\circ} \mathrm{C}$ for various strain rates (b)

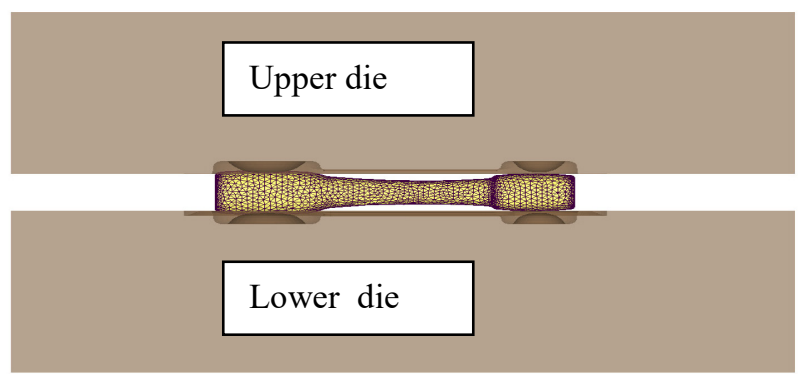

Figure 6. Geometric model for the simulation 
a)

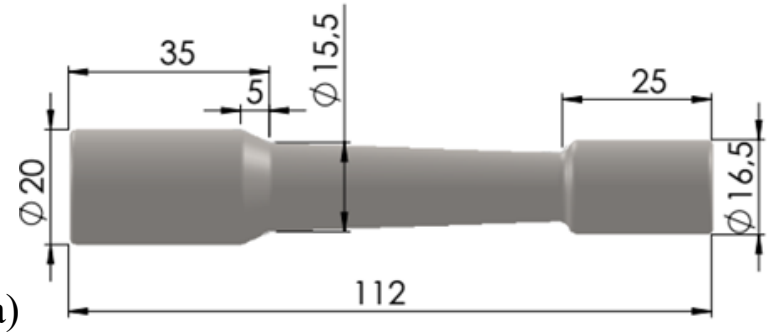

Effective Plastic Strain

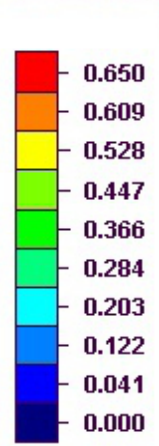

Max. 0.650

b) Min. 0.000

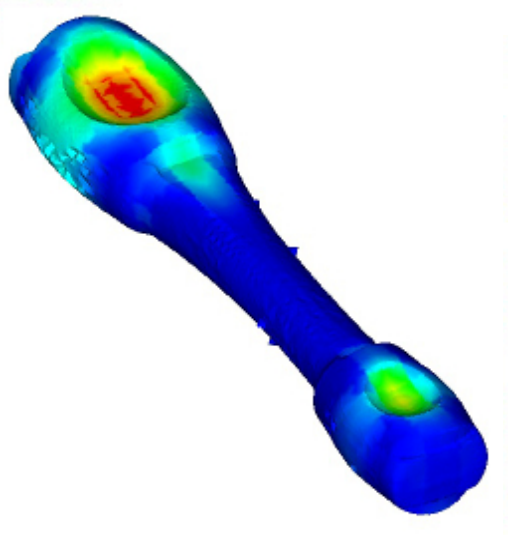

Effective Plastic Strain

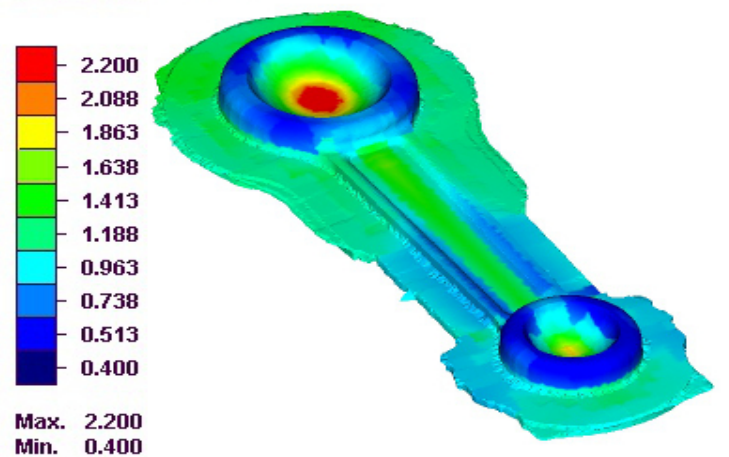

Effective Stress MPa
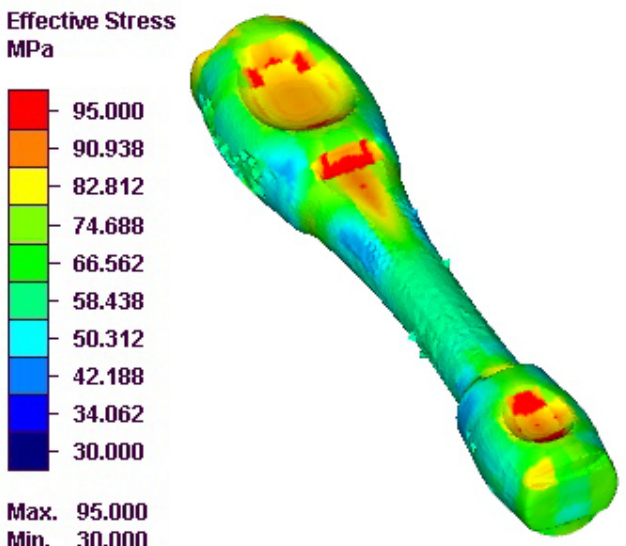

Max. 2.20

Effective Stress MPa

Max. 95.000

\begin{tabular}{|l}
\hline 180.000 \\
\hline-170.625 \\
-151.875 \\
-133.125 \\
-114.375 \\
-95.625 \\
-76.875 \\
-58.125 \\
-39.375 \\
-30.000
\end{tabular}

Max. 180.000 Min. $\mathbf{3 0 . 0 0 0}$

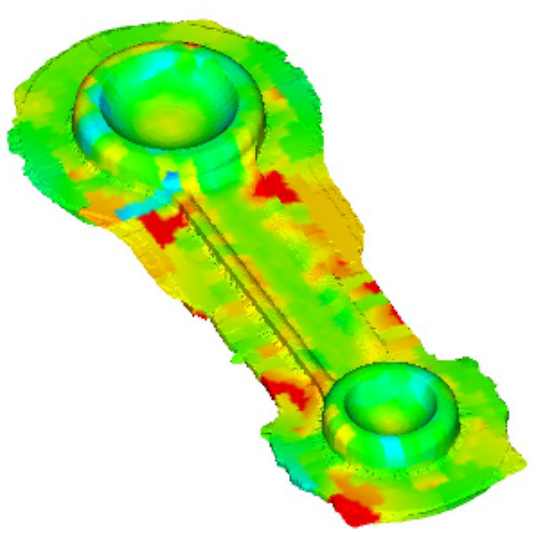

end calculation

Figure 7. Simulation results for Rebielskij type preform (Step 2), a-model of the preform for the simulation and calculated: $\mathrm{b}$ - effective strain, $\mathrm{c}$ - effective stress 
a)

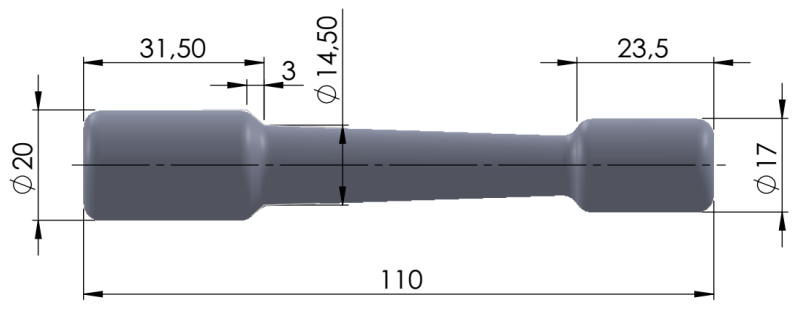

Effective Plastic Strain

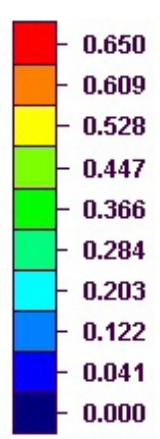

Max. 0.650

Min. $\mathbf{0 . 0 0 0}$

b)

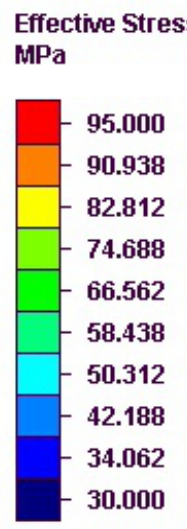

c)

Max. 95.000

Min. $\quad 30.000$

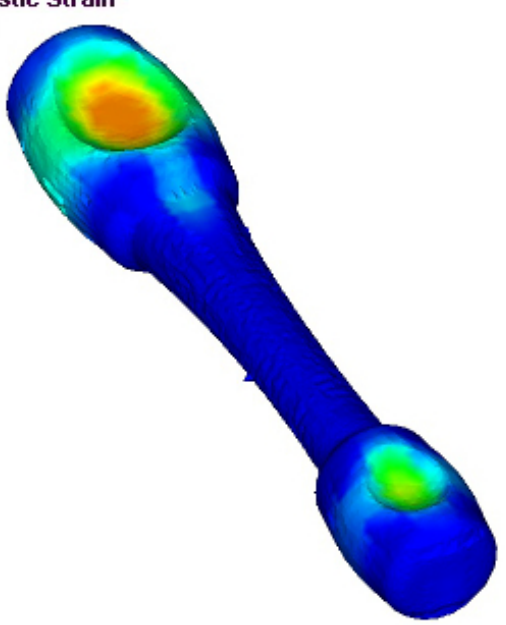

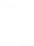

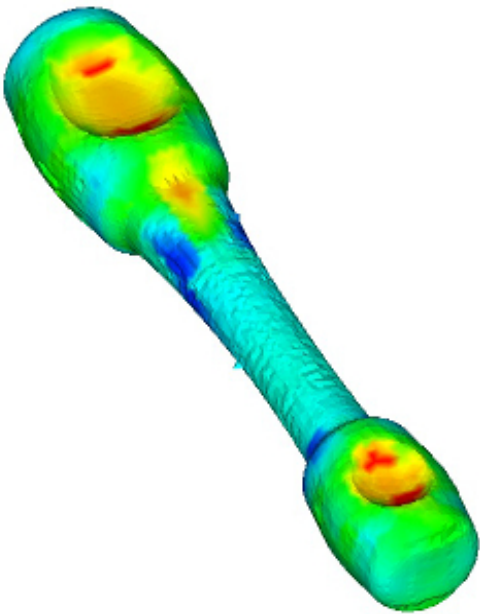

Effective Plastic Strain

Effective Stress

$\mathrm{MPa}$

$-180.000$

- 170.625

151.875

133.125

114.375

95.625

76.875

- 58.125

39.375

$-30.000$

Max. 180.000

Min. $\quad 30.000$

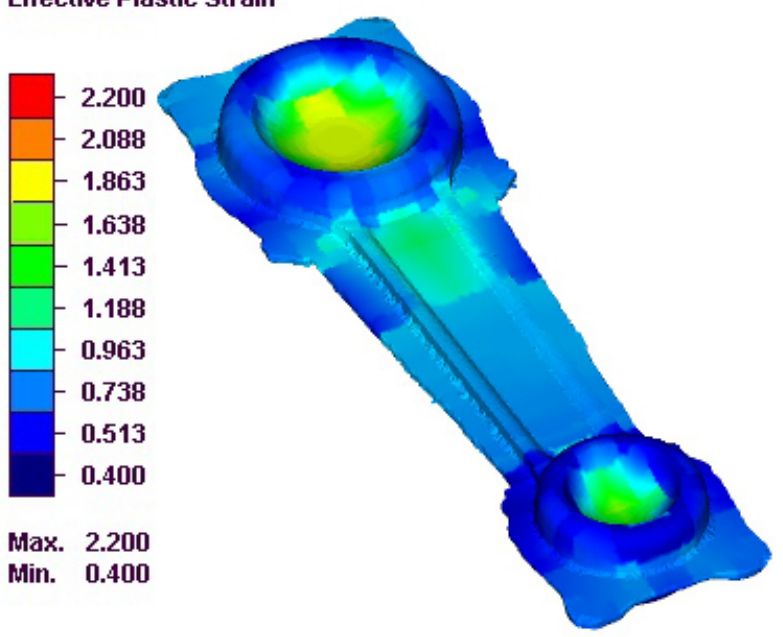

half time calculaction

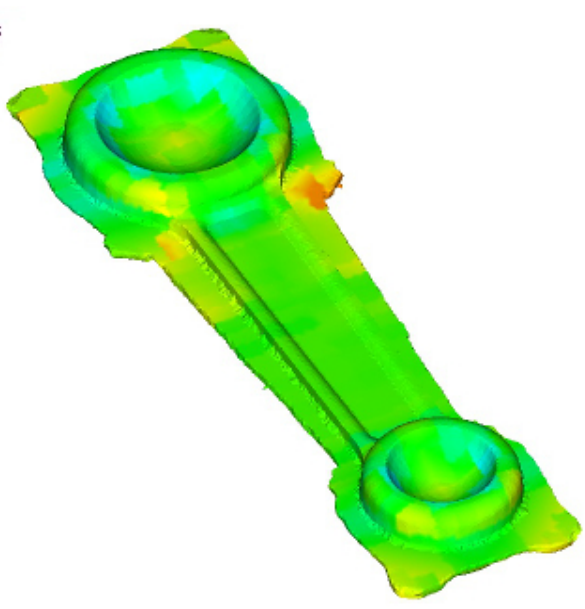

end calculation

Figure 8. Simulation results for Rebielskij corrected (Step 6) type preform, a-model of the preform for the simulation and calculated: $\mathrm{b}$ - effective strain, $\mathrm{c}$ - effective stress

Steps 3 and 4. Polymer printing of the initial models of the preform, the forging and the die.

Based on CAD code, the converted models in the STL code were prepared (Fig.9) and used to printing from polymer 3D models in stage and die on a MakerBot Replicator Z18 printer. The printed models are shown Fig. 10. 


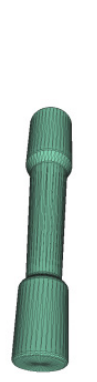

a) b)

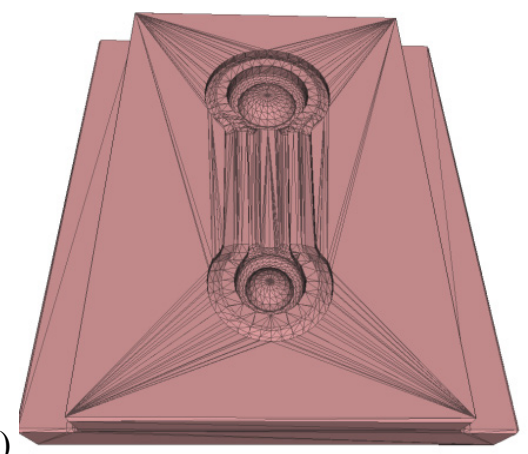

c)

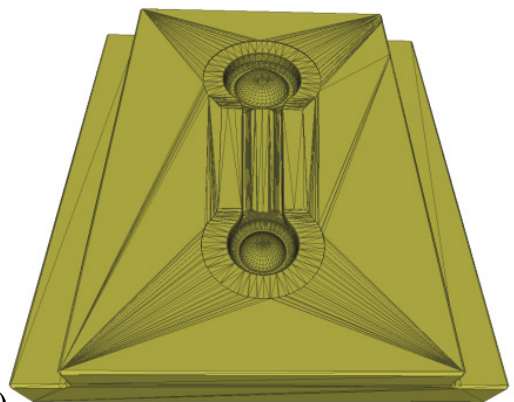

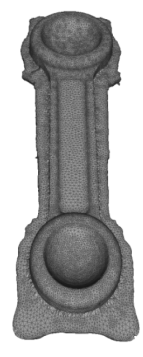

d)

Figure 9. The STL models of the: a - corrected preform, b - lower die c - upper die and c - the forging

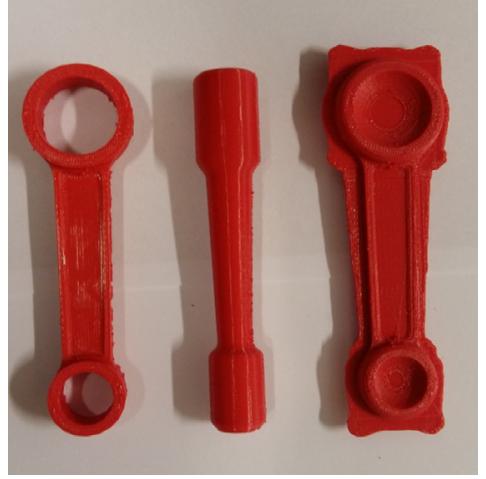

a)

b)

c)

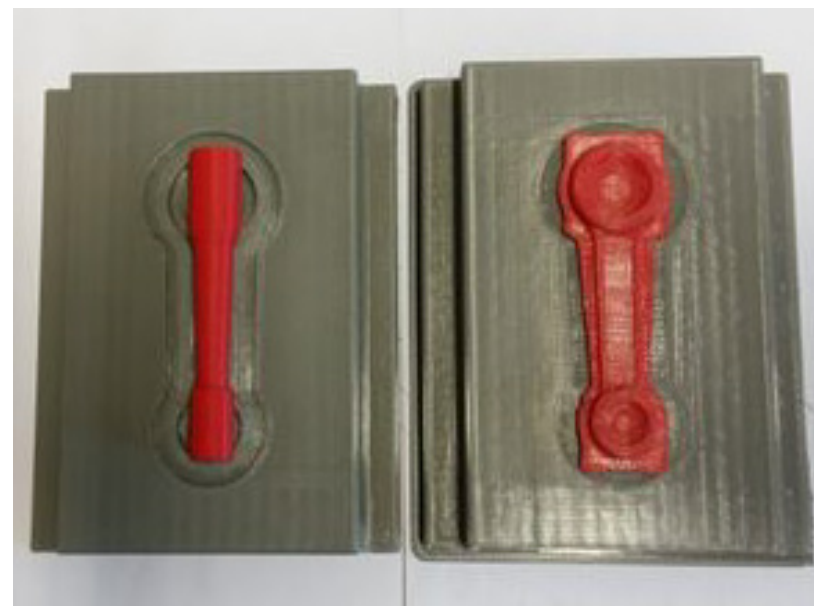

d)

e)

Figure 10. Printed models of: $\mathrm{a}$ - con rod, $\mathrm{b}$ - rolled perform corrected, $\mathrm{c}$ - forging, $\mathrm{d}, \mathrm{e}-$ preform and forging respectively in the die

\section{Discussion}

Results of the simulation were analysed, taking into account state of strain and stress, temperature distribution in the material during forming and of the forecast power and energy. These parameters are presented in Tables 1 and 2.

Table 1. Calculated range of parameters by simulation

\begin{tabular}{|c|c|c|c|c|c|c|}
\hline \multirow{2}{*}{ Variant } & \multicolumn{3}{|c|}{ Half time simulation } & \multicolumn{3}{c|}{ Finish simulation } \\
\cline { 2 - 7 } & $\mathrm{T}\left[{ }^{\circ} \mathrm{C}\right]$ & $\varepsilon_{\mathrm{eq}}$ & $\sigma_{\mathrm{eq}}[\mathrm{MPa}]$ & $\mathrm{T}\left[{ }^{\circ} \mathrm{C}\right]$ & $\varepsilon_{\mathrm{eq}}$ & $\begin{array}{c}\sigma_{\mathrm{eq}} \\
{[\mathrm{MPa}]}\end{array}$ \\
\hline Rebielskij- original & $456-488$ & $0-0.61$ & $46 \div 93$ & $401-478$ & $0.47-2.10$ & $45-182$ \\
\hline $\begin{array}{c}\text { Rebielskij after } \\
\text { correction }\end{array}$ & $460-488$ & $0-0.60$ & $37-94$ & $415-477$ & $0.38-1.07$ & $72-173$ \\
\hline
\end{tabular}

$\mathrm{T}$ - temperature, $\varepsilon_{\mathrm{eq}}$ equivalent strain, $\sigma_{\mathrm{eq}}$ - equivalent stress,

Table 2. Material consumption, forging force and energy consumption

\begin{tabular}{|c|c|c|c|c|}
\hline \multirow{2}{*}{ Variant } & \multicolumn{2}{|c|}{ Mass [kg] } & \multicolumn{2}{c|}{ Simulation } \\
\cline { 2 - 5 } & Charge & Forging & Force max. [kN] & Energy, [kJ] \\
\hline Riebelskij-original & 0.65 & 0.32 & 7.217 & 8,481 \\
\hline $\begin{array}{c}\text { Rebielskij -after } \\
\text { correction }\end{array}$ & 0.59 & 0.32 & 6.797 & 6.222 \\
\hline
\end{tabular}


More homogenous distribution of equivalent strain, stress and temperature appear in the forging after Rebielskji type - preform correction. Material consumption and calculated maximum force and energy are also smaller. Comparison of resultant polymer model forging with dimensional specifications (Fig.3b), weight and printing time is shown Table 3.

Table 3. Comparision of dimensions of designed and printed part

\begin{tabular}{|c|c|c|c|c|c|c|}
\hline Model & \multicolumn{4}{|c|}{$\mathrm{mm}$} & Weight, $\mathrm{g}$ & Printing time \\
\hline Drawn conrod & $\Phi 32.0$ & $\Phi 22.40$ & 13.0 & & & \\
\hline Printed conrod & Ф 31.8 & $\Phi 22.3$ & 13.0 & & 9.11 & $1 \mathrm{~h} 19 \mathrm{~min}$. \\
\hline Drawn preform & $\Phi 20.0$ & $\Phi 16.5$ & 35.0 & 25.0 & & \\
\hline Printed preform & $\Phi 19.6$ & $\Phi 16.5$ & 35.0 & 25.3 & 20.53 & $1 \mathrm{~h} 32 \mathrm{~min}$. \\
\hline Drawn forging & $\Phi 33.2$ & $\Phi 23.6$ & 13.0 & & & \\
\hline Printed forging & $\Phi 33.2$ & $\Phi 23.5$ & 13.3 & & 13.11 & $2 \mathrm{~h} 40 \mathrm{~min}$. \\
\hline Drawn die & 180.0 & 110.0 & 35.0 & & & \\
\hline Printed die & 178.8 & 109.4 & 35.2 & & 158.4 & 12 h 19 min. \\
\hline
\end{tabular}

\section{Summary}

3D printed polymer models of the perform, the die and the forging during processing give the possibility of verification and visualisation of the planned technological process. These models enable verification at the design stage. A cheap polymer print material may be used prior to the final technological solution with an expensive metallic material - without risk. Applying 3D printing of prototypes in the appropriate metallic materials can lead to tool manufacture and processing in industrial conditions. In this way production costs can be reduced by this new technology. This has been illustrated for a conrod.

\section{Acknowledgements}

Authors wish to express their gratitude to Emeritus Professor Andrew Wronski, University of Bradford, for comments, discussion and suggestions. These research form of the AGH in Krakow Statutory Work Program No 11.11.110.591 in 2018.

\section{References}

[1] E. Doege, B.A. Behrens, Handbuch Umformtechnik: Grundlagen, Technologien, Maschinen (in German), 2nd Edition, Springer Verlag, 2010

[2] P. Wasiunyk, Kucie matrycowe (Die forging) (in Polish), Wydawnictwa Naukowo-Techniczne, Warszawa, 1975

[3] Hirschvogel Tech Solution, Newsletter January 2018

[4] D. Schwam, B. Silwal, Applications of Additive Manufacturing in Forging, Final Report, 2017, https://www.forging.org/

[5] A.W. Rebielskij, Osnovy projektirowanija processov gorjacej objemnoj stampovki (Bases of planning processes of the die forging). Masinostrojenije, Moskva, 1965 